\title{
INTERNACIONALIZAÇÃO E TRANSNACIONALIZAÇÃO NA PÓS- GRADUAÇÃO EM EDUCAÇÃO NO BRASIL: ALGUNS EMBATES
}

\author{
ana paula Hey \\ Afrânio Mendes CatanI \\ ANTÔNIO MARCOS AMORIM \\ Universidade de São Paulo (USP), São Paulo, SP, Brasil
}

\begin{abstract}
Resumo: O artigo analisa contenciosos em torno da internacionalização da pósgraduação no Brasil, por meio do estudo de quatro Programas em Educação (PPGEs) que, na última avaliação da CAPES (2013-2016), obtiveram o conceito máximo (nota 7). Conduzindo-se um estudo exploratório cienciométrico dos artigos científicos das(os) docentes destes PPGEs, com extração de dados através do software livre scriptLattes, obteve-se um total de 1.434 artigos, sendo que, $13,9 \%$ foram publicados em revistas internacionais e, destes, $64 \%$ em inglês. A maior parte (69\%) se produziu em coautorias (dois ou mais autores). Problematizam-se aspectos da internacionalização e da transnacionalização da produção de conhecimento, visando a distinguir mecanismos formais e estratégias necessárias para trocas menos assimétricas no campo da educação.
\end{abstract}

Palavras-chave: Internacionalização. Transnacionalização. Programas de Pósgraduação em Educação. Produção científica.

\section{INTRODUÇÃO}

O fenômeno da globalização se constitui em um processo multidimensional, sendo uma das características centrais das sociedades atuais. Como expressa Martins (2015, p. 291),

\begin{abstract}
ao manifestar uma complexa intensificação de interconexões transnacionais nos planos econômico, político, cultural e acadêmico, o processo de globalização tornou-se uma potente força da produção de transformações em várias esferas da vida social contemporânea.
\end{abstract}

Nesse contexto, as atividades relativas ao mercado dos bens simbólicos, em especial a educação e a ciência, passam por fortes reconfigurações, marcadas pela ruptura com os limites das sociedades nacionais. Tal fenômeno tem merecido a atenção de pesquisadores em várias direções, mas, deve-se reservar uma dedicação especial à produção e à circulação do conhecimento. Um novo contencioso', que se pode denominar de internacionalização, tem posto em xeque formas já canônicas de 
produção e circulação do conhecimento elaborado nas diversas áreas, sobretudo no aspecto relativo à ancoragem local, tanto da produção quanto da circulação do conhecimento, bem como da centralidade do apoio institucional da universidade e das agências estatais de apoio à pesquisa.

No Brasil, é sabido que a produção científica depende de políticas e de financiamentos advindos da esfera estatal, o que resultou na organização de um sistema baseado fortemente na luta entre os vários campos científicos e seus representantes. Com a entrada desse contencioso, tende-se a mudar as estratégias institucionais e a dos pesquisadores para se adequarem a padrões estabelecidos em esferas ainda não tão objetivamente definidas, pois, ao mesmo tempo em que são fixados por meio de acordos supranacionais, também se configuram como relações quase pessoais, entre pesquisadores des-localizados e centros de pesquisa aglutinadores de cientistas globais. Para não generalizar demais os aspectos particulares dos diferentes domínios científicos, busca-se centrar em questões referentes à área de educação e de como ela pode exemplificar as mudanças em curso, as dimensões da globalização e seus efeitos na feitura institucional e na atividade prática do produtor de conhecimento. Assim, este artigo visa a indagar acerca de alguns embates envolvendo a internacionalização e a transnacionalização na pós-graduação em educação no Brasil por meio do estudo exploratório de quatro Programas de Pós-Graduação em Educação (PPGE) que obtiveram a nota máxima (7) na Avaliação CAPES para o quadriênio 2013-2016.

A educação superior tem sido profundamente afetada pela globalização, tanto em seus sistemas nacionais nos diversos países, quanto na esfera dos sistemas transnacionais que vêm se constituindo, movimentando milhares de instituições, milhões de estudantes, observando-se a presença de uma pluralidade de atores envolvidos no funcionamento do ensino superior (MARTINS, 2015, p. 291-292). Em relação à pós-graduação, polo produtor do conhecimento, não se percebe o fenômeno da mesma forma, uma vez que ele não atinge ainda uma mobilização tão acentuada de instituições e estudantes. Entretanto, intuitivamente, pode-se afirmar que a atração ao modo globalizado de formação de quadros, responsáveis pela produção de conhecimento, tende a se acentuar. Uma evidência disso têm sido as estratégias de muitas instituições privadas no fomento à internacionalização de seus estudantes no âmbito da graduação por meio de convênios com instituições estrangeiras, entre outras formas de intercâmbio, que passam a oferecer incentivos à permanência desses estudantes em seus cursos de pós-graduação. Destacando-se a facilitação dos processos seletivos de ingresso on-line; 0 incremento de novos apoios diretamente aos interessados, sem intermediação de estabelecimentos nacionais; o aumento de programas de atração de jovens talentos internacionais. Acrescente-se a isso as estratégias de muitos grupos sociais mais favorecidos em financiarem cursos de pósgraduação a seus descendentes como modo de garantir uma formação que permita maior trânsito internacional e, consequentemente, a ampliação significativa do leque de carreiras.

Com o objetivo de precisar melhor a perspectiva analítica, optou-se por utilizar o termo transnacionalização, no sentido manejado por Sapiro, Leperlier e Brahimi (2018), para caracterizar um espaço funcionando para além das fronteiras nacionais, sem ser 
HEY, A. P.; CATANI, A. M.; AMORIM, A. M.

organizado por uma instância internacional ou regional, facilitado por uma espécie de língua unificadora (o inglês) e, também, para demonstrar redes informais, forjadas quase por iniciativas individuais.

As causas da transnacionalização podem ser apontadas desde a dinâmica do capitalismo financeiro até as crises da economia global, mas seus efeitos tendem a ser bastante diversos e ainda pouco claros no que diz respeito ao mercado dos bens simbólicos. A transnacionalização da produção do conhecimento enseja uma série de perspectivas analíticas, mas destacam-se dois movimentos: de um lado o processo de intenso rearranjo institucional, em que a divisão internacional da produção científica tende a se acentuar com forte concentração em instituições de países dominantes. Por outro lado, ela produz implicações no âmbito das carreiras dos produtores, que se inclinam a dirigir suas ações mimetizando os padrões dos pesquisadores de centros e instituições mais consagrados em cada área.

Marcada pelo contexto de ampliação do acesso ao ensino terciário nos últimos 20 anos, a pós-graduação no Brasil ainda não revela o mesmo padrão. Em dados de 2018 (OCDE, 2019), constata-se que, enquanto $17 \%$ da população brasileira de 17 a 64 anos havia concluído um curso superior, apenas $0,8 \%$ concluiu o mestrado e $0,2 \%$ o doutorado, sendo que a média da OCDE relativa a este último nível é de 1,1\%. Segundo o CNPq, o Brasil possui 7,6 doutores por 100 mil habitantes, ao passo que as taxas em países como Reino Unido, Portugal, Alemanha e Estados Unidos são, respectivamente, de $41,39,7,34,4$ e 20 (SILVEIRA, 2020). Segundo o relatório Education at a glance (OCDE, 2019),

na última década, o Brasil apresentou uma melhora de 10 pontos percentuais na proporção da população de 25 a 34 anos de idade com educação superior. Em 2008, $11 \%$ da população nessa faixa etária possuía esse nível de ensino, em 2018 o percentual subiu para $21 \%$. Apesar do crescimento expressivo, o Brasil apresenta a menor proporção entre os países da América Latina: Argentina (40\%), Chile (34\%), Colômbia (29\%) e Costa Rica (28\%); todos ainda abaixo da média dos países da OCDE (44\%) (OCDE, 2019).

Mesmo que, no caso do ensino superior, a literatura aponte para um processo de transição de um modelo de ensino superior de elites para um de massas, os percentuais continuam baixos, pois, países com taxas entre $16 \%$ a $50 \%$ das matrículas se caracterizam por possuírem a configuração de ensino superior de massas (TROW, 2005). Recentemente, Altbach (2013) apontou uma expansão das taxas de matrículas brutas na faixa etária de 18 a 24 anos da população no Brasil (de 7\% para 15,5\%), ainda aquém do desejável, embora o contingente tenha dobrado em pouco mais de uma década (19992010). Esse resultado provém das iniciativas de políticas inclusivas visando ao maior acesso à educação superior, a partir de fins da década de 1990 e, em especial, nos governos de Luiz Inácio Lula da Silva (2003-2006; 2007-2010). Acrescentemos a esse ciclo, os mandatos de Dilma Rousseff (2011-2016), que permitiram a manutenção do ProUni (Programa Universidade para Todos) e algumas outras iniciativas destinadas a pessoas de baixa renda para o financiamento de estudos no ensino privado brasileiro (FIES). 
Em relação à pós-graduação, de acordo com dados extraídos da GEOCAPES (2019), em 2018 o Brasil possuía 288.590 discentes matriculados em Programas de Pósgraduação (PPGs), assim distribuídos: mestrado, 131.606, doutorado, 114.867, mestrado profissional, 42.064 e doutorado profissional, 52. Em especial às Ciências Humanas, a percentagem relativa de matrículas totais é assim representada: $23 \%$ no mestrado, $20 \%$ no doutorado e $17 \%$ no mestrado profissional, sendo que o único doutorado profissional é multidisciplinar. A distribuição por tipo de instituição é a seguinte: 170.803 $(59,2 \%)$ matriculados em universidades ou institutos federais; $73.048(25,3 \%)$ em universidades estaduais; $43.459(15,1 \%)$ em instituições particulares e $1.280(0,4 \%)$ em instituições municipais. Quanto à distribuição dos PPGs entre as instituições de nível superior, nota-se que $57,6 \%$ estão concentrados em universidades e/ou institutos federais; $23,2 \%$ em universidades estaduais públicas; $18,5 \%$ em instituições privadas e $0,7 \%$ em institutos municipais. Em relação a 2014, o total de pós-graduandos decresceu $4,45 \%$ (eram 302.034 estudantes no total), provavelmente em virtude da crise instaurada nas políticas de $C \& T$ no país, o que inclui a frágil atuação do setor privado tanto no financiamento quanto na empregabilidade de mão de obra mais qualificada. Acrescente-se também a fragilização do Sistema Nacional de Pós-graduação (SNPG), com instabilidade de apoio financeiro a pesquisadores, discentes, programas e fomentos a publicações, eventos e intercâmbios.

Ao invés de um movimento de expansão da pós-graduação, constata-se muito mais uma dinâmica de distanciamento entre áreas do conhecimento e setores com mais possibilidades de financiamento, tais como a pesquisa com ênfase em produção tecnológica (biotecnologia, agronegócio, inteligência artificial) e os domínios de reconhecimento social mais imediatos (tratamento de doenças, medicamentos, agricultura). A pós-graduação ainda aparece como um nicho exclusivo do sistema público, mas sujeita a uma reorganização dada pela divisão internacional do trabalho científico, que busca impelir as instituições e as carreiras de pesquisadores a ditames internacionais de aferição, como avaliação por métricas e conformidade da produção científica às leis dominantes ditadas pelas publicações de maior prestígio. Nesse contexto, a internacionalização assume a tônica das estratégias institucionais, impactando nas carreiras dos pesquisadores, trazendo um misto de inserção na dinâmica da transnacionalização da produção do conhecimento e de colocação nesse mercado de produção simbólica, sujeito a leis exógenas determinadas pelos polos dominantes para sua produção e divulgação.

\section{A AVALIAÇÃO PELA CAPES DOS PROGRAMAS DE PÓS-GRADUAÇÃO}

A avaliação sistemática dos Programas de Pós-graduação no Brasil foi instituída pela CAPES (Coordenação de Aperfeiçoamento de Pessoal do Ensino Superior) em 1977. Tal avaliação transforma em indicadores o conjunto das diversas atividades acadêmicas desenvolvidas no âmbito de cada um dos Programas que mantém e, para o que nos interessa no presente artigo, os cursos stricto sensu em níveis de Mestrado e de Doutorado. Ao longo do tempo, o processo como um todo foi aperfeiçoado, instituindose o Conselho Técnico-Científico da Educação Superior (CTE-ES) e as Comissões de 
HEY, A. P.; CATANI, A. M.; AMORIM, A. M.

Assessores por área para executar a avaliação e o acompanhamento dos cursos. Hoje, esse sistema de avaliação dos PPGs classifica os programas em uma variação de 1 a 7 (antes eram letras, de $\mathrm{E}$ até $\mathrm{A}$ ) e diz que

os programas recebem notas na seguinte escala: 1 e 2, têm cancelada as autorizações de funcionamento e o reconhecimento dos cursos de mestrado e/ou de doutorado por eles oferecidos; 3 significa desempenho regular, atendendo ao padrão mínimo de qualidade; 4 é considerado um bom desempenho e 5 é a nota máxima para programa com apenas mestrado. Notas 6 e 7 indicam desempenho equivalente ao alto padrão internacional (CAPES, 2017a apud AZEVEDO; CATANI; HEY, 2017, p. 299-300).

A importância da internacionalização para a área de Educação da CAPES, referente ao quadriênio 2013-2016, pode ser lida no Relatório de Avaliação aprovado pelo CTC-ES:

As notas 6 e 7 foram reservadas exclusivamente para os Programas com doutorado que obtiveram nota 5 e conceitos MB [Muito Bom] em todos os quesitos da ficha de avaliação e que atendem prioritariamente às seguintes condições: a) desempenho equivalente aos centros internacionais de excelência na área; b) nível de desempenho diferenciado em relação aos demais Programas da área; c) solidariedade e nucleação (...). Os Programas 6 e 7 demonstraram elevado grau de solidariedade, examinados por meio dos seguintes indicadores: 1 . Eventos e cursos internacionais; 2. Intercâmbios; 3. Editoração; 4. Redes internacionais; 5. Financiamento e premiações; 6 . Inserção acadêmica e impacto local da internacionalização (CAPES, 2017a, p. 54-56).

Os indicadores mencionados encontram-se assim compostos: 1. Eventos e cursos internacionais: 1.1 Realização de eventos com professores estrangeiros; 1.2 Recebimento de eventos internacionais; 1.3 Recebimento de cursos de professores estrangeiros. 2. Intercâmbios: 2.1 Participação com financiamento de professor estrangeiro visitante no Programa; 2.2 Participação sem financiamento de professor estrangeiro visitante no Programa; 2.3 Participação de professor do Programa como visitante em universidade estrangeira; 2.4 Realização de Mestrado e Doutorado Sandwich; 2.5 Coordenação internacional; 2.6 Professores do Programa em pósdoutorado internacional; 2.7 Oferecimento de cursos ou vagas no Programa a estrangeiros. 3. Editoração: 3.1 Publicação com parceiros internacionais; 3.2 Publicação em periódicos internacionais; 3.3 Atuação como editor de periódico internacional. 4. Redes internacionais: 4.1 Composição de redes internacionais de pesquisa; 4.2 Composição de projetos internacionais de pesquisa. 5. Financiamento e premiações: 5.1 Obtenção de financiamento de agência internacional; 5.2 Premiações internacionais. 6. Inserção acadêmica e impacto local da internacionalização: 6.1 Gestão científica de órgão internacional; 6.2 Benefício da internacionalização para a graduação.

Não é demais salientar, como mencionado em outro trabalho (AZEVEDO; CATANI; HEY, 2017, p. 300), que a política de avaliação da CAPES reflete, de maneira geral, o que preconiza o Plano Nacional de Pós-Graduação - PNPG (2010-2020), 
ressaltando na introdução que "a exemplo dos Planos anteriores, também neste a busca da Internacionalização continuará sendo uma das metas maiores do sistema" (CAPES, 2010, p. 21). Como é sabido por aqueles que interagem no campo acadêmico, os programas de pós-graduação conceituados nas escalas 6 e 7, as duas maiores, "recebem maior financiamento e possuem maior autonomia de gestão financeira por intermédio do Programa de Excelência Acadêmica - PROEX da CAPES". O PROEX objetiva "manter o padrão de qualidade dos programas de pós-graduação com nota 6 e 7, pertencentes a instituições jurídicas de direito público e privado, atendendo adequadamente suas necessidades e especificidades" (CAPES, 2017b). Seguindo a mesma lógica de classificação e procurando estabelecer uma hierarquia no Sistema de Pós-Graduação, o PNPG 2011-2020 preconiza tratamento diferenciado para os Programas de PósGraduação que possuem estas notas máximas em futuras avaliações:

Os cursos 6 e 7, que ocupam o topo do sistema, poderão beneficiarse de uma desregulamentação parcial em suas atividades, permitindo a busca do novo e de experimentações, com o acompanhamento de avaliadores estrangeiros, ficando o monitoramento mais estrito reservado aos demais programas (CAPES, 2010, p. 22).

No que diz respeito ao financiamento,

os Programas inseridos no PROEX recebem uma dotação orçamentária que pode ser utilizada de acordo com prioridades estabelecidas pelos próprios programas, em qualquer das modalidades de apoio concedidos pela CAPES: concessão de bolsas de estudo, bem como recursos de custeio fomento para investimento em laboratórios, custeio de elaboração de dissertação e teses, passagens, eventos, publicações, entre outros. As bolsas de estudo concedidas no âmbito do Proex são gerenciadas pelas coordenações dos cursos de pós-graduação (CAPES, 2017b).

Assim, em fins de 2017 foi divulgado pela CAPES o resultado da avaliação quadrienal (2013-2016), havendo imensa frustração em vários programas de Educação e grande euforia nos poucos que receberam a nota 7 - casos da Universidade Federal de Minas Gerais (UFMG), da Universidade do Vale do Rio dos Sinos (UNISINOS), da Universidade do Estado do Rio de Janeiro (UERJ) e da Pontifícia Universidade Católica do Rio Grande do Sul (PUC-RS). O PPG da Faculdade de Educação da Universidade de São Paulo (USP), por exemplo, teve sua nota rebaixada de 6 para 5, perdendo o financiamento do PROEX e passando a ser regulado, portanto, pelas normas do Programa de Apoio à Pós-Graduação (PROAP), tendo redução de financiamento e enfrentado crises e cisões ${ }^{2}$. 
HEY, A. P.; CATANI, A. M.; AMORIM, A. M.

\section{A INTERNACIONALIZAÇÃO DOS PROGRAMAS DE PÓS-GRADUAÇÃO EM EDUCAÇÃO}

Em um período marcado pela transnacionalização da produção do conhecimento, há que se observar os distintos níveis em que isso se processa, ou seja, o das instituições, o dos pesquisadores e o dos discentes. Diferentes políticas, nem sempre delineadas claramente, atingem de modo desigual esses atores, ocorrendo, em muitos casos, o estabelecimento de estratégias particulares para atingir a finalidade da internacionalização. Por exemplo, Audy e Morosini (2010), expondo as boas práticas relativas à internacionalização da PUC-RS, condensam um plano de ação nesse quesito implementado pela instituição. Todavia, devem ser consideradas as enormes disparidades entre os tipos de instituições e mesmo entre as diferentes regiões nas quais elas se localizam, aumentando ou não a possibilidade de êxito desses planejamentos. $\mathrm{Na}$ esfera dos câmbios característicos de um processo de transnacionalização da produção de conhecimento, Azevedo e Catani (2013) assinalam que a troca de saberes implica

em compartilhamento de cultura e de conhecimento. Isso pode ocorrer tanto em nível restrito, para as elites [e entre as elites], quanto de maneira ampla, sem discriminação de classes; tanto em plano nacional, com vista à unificação, como internacional, para a promoção da solidariedade [e educação] dos povos (AZEVEDO; CATANI, 2013, p. 274, grifo nosso).

E Santim, Vanz e Stumpf (2016) afirmam, em relação à internacionalização no meio científico, que esta

[...] pode ser associada a diversos fatores, entre os quais se destacam a crescente complexidade e a interdisciplinaridade das pesquisas; os avanços das tecnologias de informação e comunicação; a facilidade de mobilidade global; as políticas e os instrumentos de cooperação internacional; e a ampliação da colaboração entre autores e instituições do mundo todo (SEBASTIÁN, 2008). O processo de internacionalização está condicionado às especificidades de cada área, país ou instituição, com suas culturas de publicação [...] (SANTIN; VANZ; STUMPF, 2016, p. 85).

Referindo-se de modo mais direto, a circulação transfronteiriça do conhecimento tende a ser o modo de visualização da troca de saberes, portanto, a publicação em periódicos internacionais ganha relevo. Além disso, ao se considerar os critérios de avaliação dos PPGs no país - e os da Educação, em especial - observa-se a tendência de se ter como um de seus pilares ou metas a exacerbação das publicações em periódicos, considerados internacionais, como diferenciador da classificação dos distintos programas. Embora a produção científica carregue uma tipologia, entre artigos científicos (locais, regionais, internacionais), livros, capítulos de livros, trabalhos em congressos, teses, patentes, trabalhos técnicos etc., ganha maior notoriedade aquela que também propicia o mais elevado patamar na avaliação oficial. A ênfase nos artigos científicos caracteriza as Ciências Exatas, Biológicas e da Saúde ('hard science), gerando uma hierarquia desfavorável à multiplicidade de produções que marcam as 
Humanidades e as Ciências Sociais Aplicadas ('soft science), conforme apontam vários estudos cienciométricos - vide Mugnaini, Leta e Leite (2011).

O Portal de Periódicos da CAPES revela que a produção científica brasileira passou de 19.436 artigos em 2007 para 30.451 publicações em 2008, fazendo com que o país alcançasse a 13 a posição na classificação mundial em produção científica nesse ano, ultrapassando a Rússia (15a) e a Holanda (14a). A classificação geral envolvendo os 12 maiores produtores é a seguinte: Estados Unidos, China, Alemanha, Japão, Inglaterra, França, Canadá, Itália, Espanha, Índia, Austrália e Coréia do Sul. Não é supérfluo lembrar que "o desempenho alcançado pelo Brasil é resultado da ação das universidades e centros de pesquisa que atuam na pós-graduação universitária" (CAPES, Portal de Periódicos).

Os acadêmicos brasileiros vinculados aos PPGs divulgam os resultados de seu trabalho de investigação, fundamentalmente, em periódicos científicos de suas respectivas áreas. No domínio da educação, segundo o Qualis Periódicos ${ }^{3}$, as revistas classificadas como A1, ou seja, de caráter internacional, alcançam um total de 121 títulos, sendo editadas em diferentes países, mas com predominância do Brasil.

O Qualis Periódicos da CAPES tornou-se parte do sistema de avaliação dos programas de pós-graduação justamente por mensurar a produção científica que constitui a base da diferenciação das notas dos programas, mas também, por ser um modelo consolidado de classificação ou ranking das revistas científicas brasileiras que prioriza aquelas com notas Qualis A1, responsáveis pela maioria dos artigos internacionais publicados com algum impacto, produzido nas diferentes áreas do conhecimento, inclusive, nas Humanidades (OLIVEIRA; AMARAL, 2007). Tal aplicação e modelo também compõem embates entre os diferentes campos científicos, sendo que indicadores bibliométricos que medem o fator de impacto (FI) das citações dos periódicos, em bases de dados como a Web of Science (WoS) da empresa Clarivate Analytics, Scopus da Elsevier e o Google Scholar (H5 ou H10), buscam substituir a métrica atual, consolidando-se como fontes de referência global à análise, não somente dos próprios indicadores cienciométricos, mas, sobretudo, para a avaliação da produção científica nos últimos anos (LEYDESDORFF et al., 2016).

Em relação aos indicadores concernentes às publicações como parâmetro da internacionalização da ciência, Santin, Vanz e Stumpf (2016, p. 89) reforçam que

[...] a indexação é [...] um requisito de visibilidade dos periódicos no cenário internacional. Nessa perspectiva, toda a produção científica brasileira indexada em bases de dados como a Web of Science, a SCOPUS e a PubMed, por exemplo, pode ser considerada internacionalizada.

Assim, tendo como pressuposto que as publicações vêm assumindo um forte papel para diferenciar os programas, ao mesmo tempo em que mensuram sua internacionalização e, como defendemos, sua forma de transnacionalização, apresentam-se os primeiros resultados de uma pesquisa exploratória. Foram detectados nos quatro PPGEs com nota 7 na avaliação da CAPES, para o quadriênio 2013-2016 - 
como já citado, UERJ, UNISINOS, UFMG e PUC-RS -, elementos acerca da publicação internacional desses programas.

Os quadros a seguir buscam demonstrar um conjunto de argumentos que está sendo desenvolvido.

Quadro 1 - Totais gerais de artigos publicados pelos PPGs em Educação, subtotais de artigos em revistas internacionais, seus respectivos percentuais e a média de artigos por docente de cada programa.

\begin{tabular}{|c|c|c|c|c|c|}
\hline Instituição & $\begin{array}{c}\text { Total de Artigos } \\
\text { publicados (2013- } \\
\text { 2016) }\end{array}$ & $\begin{array}{c}\mathbf{N}^{\mathbf{0}} \text { de } \\
\text { Docentes no } \\
\text { PPGE }\end{array}$ & $\begin{array}{c}\mathbf{N}^{\mathbf{0}} \text { artigos } \\
\text { internacionais }\end{array}$ & $\begin{array}{c}\text { \% Artigos } \\
\text { internacionais }\end{array}$ & $\begin{array}{c}\text { Média de } \\
\text { Artigos } \\
\text { internacionais } \\
\text { por Docente }\end{array}$ \\
\hline UERJ & 370 & 46 & 53 & $14,3 \%$ & 1,15 \\
\hline UNISINOS & 201 & 16 & 30 & $14,9 \%$ & 1,88 \\
\hline UFMG & 652 & 96 & 58 & $8,9 \%$ & 0,60 \\
\hline PUC-RS & 211 & 17 & 58 & $27,5 \%$ & 3,41 \\
\hline Totais & 1.434 & 175 & 199 & -- & - \\
\hline
\end{tabular}

Fonte: Os autores.

As informações do Quadro 1 demonstram o total geral de 1.434 artigos publicados pelos quatro PPGEs avaliados, dos quais 199 (13,88\%) correspondem a artigos internacionais. Observa-se ainda uma variação entre 0,60 (UFMG) e 3,41 (PUC-RS) de artigos internacionais por docente, apontando o grau de aderência dos pesquisadores à visibilidade científica internacional no período de 2013 a 2016. Observase ainda significativa diferença no que se refere ao corpo docente das instituições públicas (UERJ e UFMG) e das privadas (UNISINOS E PUC-RS): a UFMG, por exemplo, possui 6 vezes mais professores credenciados junto ao PPGE do que a UNISINOS proporção quase igual quando se compara ainda com a PUC-RS. Por sua vez, os 46 docentes credenciados junto à UERJ correspondem a quase três vezes mais àqueles credenciados da UNISINOS, e também, da PUC-RS.

Quanto ao número de artigos internacionais produzidos no âmbito desses quatro programas, as diferenças são notórias, indicando que os docentes da PUC-RS produzem quase seis vezes mais que os da UFMG e três vezes mais que os da UERJ. Os professores credenciados da UNISINOS, por seu turno, têm média de artigos internacionais por docente mais de três vezes superior aos da UFMG, um pouco superior à metade dos da PUC/RS e mais de $50 \%$ superior aos de seus colegas da UERJ. De qualquer maneira, a média de mais de três artigos internacionais por docente lavrada pela PUC/RS se constitui em marca relevante. Isso pode ser resultante da política da instituição nesse quesito, como já exposto anteriormente no trabalho de Audy e Morosini (2010), mas também da reformulação dos PPGEs nos últimos 10 anos em direção a uma diminuição dos quadros de pesquisadores como forma de controle mais 
acirrado da produção acadêmica, visando à melhoria dos índices oficiais e a atração de financiamentos e novos discentes.

Quadro 2 - Totais e percentuais respectivos de artigos publicados em revistas internacionais nos PPGEs analisados, respectivos totais por $n^{\circ}$ de autores (individuais ou em coautoria), e no de citações recebidas pelo Google Acadêmico, extraídos com o software scriptLattes (2013-2016).

\begin{tabular}{|c|c|c|c|c|c|c|c|}
\hline Instituição & $\begin{array}{c}\mathbf{N}^{\mathbf{0}} \text { artigos } \\
\text { internacionais } \\
(\mathbf{2 0 1 3 - 2 0 1 6 )}\end{array}$ & $\begin{array}{c}\text { \% do Total } \\
\text { de Artigos }\end{array}$ & $\begin{array}{c}\text { Com 1 } \\
\text { autor }\end{array}$ & $\begin{array}{c}\mathbf{C o m} \mathbf{2} \\
\mathbf{a} \mathbf{3} \\
\text { autores }\end{array}$ & $\begin{array}{c}\text { Com 4 } \\
\text { autores } \\
\text { ou mais }\end{array}$ & $\begin{array}{c}\mathbf{N}^{\mathbf{0}} \text { citações } \\
\text { no Google } \\
\text { Acadêmico }\end{array}$ & $\begin{array}{c}\mathbf{N}^{\mathbf{0}} \text { artigos com 4 } \\
\text { ou citações no } \\
\text { Google } \\
\text { Acadêmico }\end{array}$ \\
\hline UERJ & 53 & $14,3 \%$ & 26 & 24 & 3 & 126 & 10 \\
\hline UNISINOS & 30 & $14,9 \%$ & 7 & 18 & 5 & 133 & 11 \\
\hline UFMG & 58 & $8,9 \%$ & 16 & 36 & 6 & 364 & 19 \\
\hline PUC-RS & 58 & $27,5 \%$ & 12 & 36 & 10 & 255 & 24 \\
\hline Totais & $\mathbf{1 9 9}$ & -- & $\mathbf{6 1}$ & $\mathbf{1 1 4}$ & $\mathbf{2 4}$ & $\mathbf{8 7 8}$ & $\mathbf{6 4}$ \\
\hline
\end{tabular}

Fonte: Os autores.

Conforme aponta o Quadro 2, dos quatro PPGEs analisados, observam-se que as respectivas produções científicas em revistas internacionais foram realizadas predominantemente em regime de coautoria, envolvendo dois a três autores (114 dos 199 artigos ou 57,3\%). Há 61 artigos internacionais com autoria única, ou seja, 30,7\% do total, e apenas 24 artigos (12,0\%) escritos por quatro ou mais autores. Assim, 69,3\% dos artigos foram escritos em regime de coautoria, o que indica que a área educacional, a exemplo de várias outras classificadas como hard sciences, cujos artigos possuem muitos autores, uma vez que a produção científica é desenvolvida fundamentalmente em laboratórios e com forte divisão do trabalho prático de pesquisa, tem se valido desse mecanismo. Sendo esta a forma predominante de se divulgar a ciência na atualidade, a partir do modelo dominante, resta saber se esse procedimento se constitui em estratégia de inserção internacional ou se, de fato, o trabalho intelectual resulta do estabelecimento de uma forma de divisão que mimetiza a produção das áreas consagradas.

No que se refere aos totais de citações no Google Acadêmico, há menor variação entre os PPGEs em valores absolutos: estes possuíam entre 126 citações recebidas por artigos oriundos da UERJ e 364 citações vindas de textos da UFMG, passando por 255 da PUC-RJ e 133 da UNISINOS. Aqueles com quatro ou mais menções representam $32,4 \%$ de toda a produção internacional em periódicos científicos $\mathrm{A} 1$ geradas por estes PPGs em Educação. Embora a UFMG tenha percentualmente um número menor de artigos internacionais publicados em relação aos nacionais $(8,9 \%)$, o número de citações apresentado exprime um fator de impacto bem maior do que o demonstrado pelos números absolutos das publicações. $O$ que reforça a diferença em medir fatores de impacto e o número de artigos produzidos no que diz respeito à 
circulação do conhecimento, podendo trazer novas clivagens ao campo em período próximo.

Por meio das métricas da ciência, pode-se verificar que as estratégias de internacionalização da produção tendem a seguir o padrão da validade do que se produz na área, uma vez que se cumpre o requisito dado pela CAPES relativo ao número de autores que 'valem' em uma publicação - no máximo três autores. Mais do que significar uma transnacionalização do conhecimento em moldes de feitura de projetos coletivos e redes de divulgação, seguem uma norma de classificação oficial para serem enquadrados nos extratos superiores de avaliação do programa.

Quadro 3 - Totais de artigos científicos internacionais publicados nos cinco principais idiomas dos PPGEs de 2013 a 2016.

\begin{tabular}{|c|c|c|c|c|c|c|}
\hline Instituição & $\begin{array}{c}\mathbf{N}^{\mathbf{0}} \text { de artigos } \\
\text { internacionais }\end{array}$ & $\begin{array}{c}\mathbf{N}^{\mathbf{0}} \mathbf{d e} \\
\text { artigos em } \\
\text { Inglês }\end{array}$ & $\begin{array}{c}\mathbf{N}^{\mathbf{0}} \text { de artigos } \\
\text { em Espanhol }\end{array}$ & $\begin{array}{c}\mathbf{N}^{\mathbf{0}} \mathbf{d e} \\
\text { artigos em } \\
\text { Francês }\end{array}$ & $\begin{array}{c}\mathbf{N}^{\mathbf{o}} \text { de artigos } \\
\text { em Português }\end{array}$ & $\begin{array}{c}\mathbf{N}^{\mathbf{0}} \mathbf{d e} \\
\text { artigos em } \\
\text { Italiano }\end{array}$ \\
\hline UERJ & 53 & 29 & 16 & 3 & 2 & 3 \\
\hline UNISINOS & 30 & 18 & 7 & 1 & 1 & 2 \\
\hline UFMG & 58 & 34 & 14 & 9 & 0 & 1 \\
\hline PUC-RS & 58 & 46 & 11 & 1 & 0 & 0 \\
\hline Totais & $\mathbf{1 9 9}$ & $\mathbf{1 2 7}$ & $\mathbf{4 8}$ & $\mathbf{1 4}$ & $\mathbf{3}$ & $\mathbf{6}$ \\
\hline & $\begin{array}{c}\text { Percentuais } \\
\text { por idioma }\end{array}$ & $64 \%$ & $24 \%$ & $7 \%$ & $2 \%$ & $3 \%$ \\
\cline { 2 - 7 }
\end{tabular}

Fonte: dos autores.

O Quadro 3 mostra o conjunto da produção de artigos científicos dos PPGEs, classificados em cinco idiomas. Há a predominância da língua inglesa (64\% ou mais da metade), seguida de artigos em espanhol (24\%) e em francês (7\%), como idiomas mais frequentes, em ordem decrescente 4 . A forma adotada do contencioso da internacionalização elege a língua inglesa como modus operandi da inserção internacional, como se bastasse a publicação no idioma dominante para tornar-se presente em fatores de impacto. A literatura tem apontado, todavia, o processo de concentração da produção científica e o estabelecimento de uma verdadeira economia das publicações e citações, que depende de como os países não dominantes se inserem na divisão do trabalho científico. Quanto mais dominante é um país em determinada área, maior é a proporção de citações dos trabalhos produzidos no próprio território. Nos Estados Unidos, em Ciências Sociais, é reservado somente 1/3 de suas referências a trabalhos estrangeiros, uma vez que a autonomia de recursos (financeiros e humanos) torna-os menos propensos a trocas internacionais, insulares e com um nível elevadíssimo de autossuficiência em relação a outros países, como observado por Sapiro (2009). Esse aspecto traz à tona a problemática da 'universalização das condições de acesso ao universal', aponta Bourdieu (1994) apud Wagner (2017), como básica na análise das dinâmicas de internacionalização e transnacionalização da produção do conhecimento e tema a ser enfrentado de modo específico nos distintos campos científicos. 
Conforme relatório da Scimago (SCImago, 2019), responsável pela base de dados SCOPUS, o Brasil produziu de 1996 a 2018 (durante 22 anos) um total de 938.352 trabalhos científicos em todas as áreas do conhecimento, e se manteve na 15 a posição do ranking mundial de 2016. Ainda, encontra-se à frente de todos os outros países da América Latina, tendo saltado de 669.280 trabalhos científicos indexados na SCOPUS em 2015 para o número atual. As mais de 10 milhões de citações recebidas representam uma média de 10,90 citações por documento publicado, com incremento de $40,2 \%$ na produção científica brasileira em apenas 5 anos. De modo semelhante, e comparativamente, na base de dados Web of Science, considerando-se o período de 2009 a 2019 (Clarivate Analytics, 2019), o Brasil figura na 13a posição no ranking mundial de trabalhos científicos, totalizando 435.687 trabalhos publicados com 3.981 .982 citações auferidas ou $1,58 \%$ de toda produção científica mundial. Assim, os números advindos da Web of Science são menores, uma vez que é considerada uma base mais elitista, embora ambas sejam multidisciplinares. Nela, o Brasil se encontra na $35^{\mathrm{a}}$ posição, atrás dos países que compõem o BRICS, como a Rússia (13a posição), a Índia (9a posição), com exceção da África do Sul. A China passou a ocupar a 2a posição mundial (SClmago, 2019), com 5.901.404 artigos científicos publicados no período. Especificamente na área da educação, o relatório da SCImago assinala que no total se publicaram 13.580 artigos científicos, colocando o Brasil na $8^{a}$ posição do ranking mundial de trabalhos produzidos neste domínio em 2019, à frente de nações muito mais fortes e tradicionais em pesquisas, como Holanda, França, Japão e Itália (esta em $14^{\circ}$ lugar).

O grau de internacionalização, porém, não pode ser aferido apenas pelas políticas de publicação ou contagem de citações de forma isolada. Devem ser analisados, no âmbito dos PPGEs, nos intercâmbios institucionais implementados, responsáveis por determinar a execução de diretrizes em consonância com as instituições conveniadas, bem como no grau de relevância de tais práticas e políticas em cada programa.

Ainda que parte considerável das universidades brasileiras esteja longe de alçar a esses mecanismos, observa-se que os PPGEs realizam, de forma majoritária, ações pontuais, tais como a recepção de alunos estrangeiros, a concessão de bolsas-sanduíche, os estímulos à realização da pós-graduação no exterior, as trocas com professores visitantes e as missões de brasileiros no exterior (via pós-doutorado, geralmente). Esse conjunto de práticas ainda carece de um plano político nacional em duas frentes: nos pós-graduandos, fomentar a promoção de maior interface com o saber e a cultura locais, a partir dos convênios firmados; nos docentes, estimular o estabelecimento de cooperações efetivas entre os pesquisadores, sobretudo no que se refere à produção de novos conhecimentos.

Tais ações podem ser efetivadas na forma de artigos científicos em coautoria e em projetos inovadores desenvolvidos entre instituições nacionais e em redes transnacionais. Mas, vale lembrar que esse espaço de relações multidimensionais é pautado por disputas e pela distribuição típica dos diferentes tipos de capital que caracterizam o campo científico. Bourdieu (2017, p. 53) assim o expõe, 
HEY, A. P.; CATANI, A. M.; AMORIM, A. M.

\begin{abstract}
o peso associado a um agente, suportado pelo campo ao mesmo tempo que contribui para o estruturar, depende de todos os outros agentes, de todos os outros pontos do espaço [científico] e das relações entre todos os pontos, ou seja, de todo o espaço (quem conheça os princípios de análise das correspondências múltiplas perceberá a afinidade entre este método de análise matemática [e também cienciométrica] e o pensamento em termos de campo).
\end{abstract}

Desse modo, existe uma hierarquia tácita que direciona as ações típicas a serem validadas no campo da produção de conhecimento, em que estratégias adotadas na disputa pela posição vão resultar em maior ou menor probabilidade de sucesso, assim ressaltada por Bourdieu (1975, p. 117-118),

a cada momento, existe uma hierarquia social dos campos científicos (as disciplinas) que direciona as práticas e, particularmente, as 'escolhas' de 'vocação'. No interior de cada um dos campos há uma hierarquia social dos objetos e métodos de tratamento. As discussões sobre a prioridade das descobertas opõem, em mais de um caso, aquele que descobriu o fenômeno desconhecido sob a forma de uma simples anomalia ou falha nas teorias existentes, e aquele que faz do fato desconhecido um fato científico novo, inserindo-o numa construção científica irredutível ao dado bruto.

Inseridos nesta problemática, a maioria dos PPGs em Educação situa-se ainda em etapas iniciais de sua internacionalização e depende de acordos que envolvem o capital político e social dos seus pesquisadores, bem como de suas posições relativas no mundo acadêmico global. A transnacionalização poderia significar a busca de intercâmbios mais efetivos, que pudessem romper a lógica da hierarquia dada no campo científico em que todas as áreas disputam a mesma posição no espaço global.

\title{
CONSIDERAÇÕES FINAIS
}

Ao se falar de internacionalização no âmbito de pós-graduação brasileira constata-se que ela assume a via da publicação em periódicos internacionais como estratégia de colocação em um mercado simbólico específico. Todavia, há o risco de se negligenciar a feitura de uma boa ciência local em prol de ações nem sempre favoráveis à dinâmica da fronteira nacional. Deve-se lembrar ainda que ela pode servir para hierarquizar diferentemente a produção nacional, isto é, alçar aquelas menos relevantes na hierarquia nacional ao status de uma produção internacionalizada.

A internacionalização, vista como contencioso, traz à tona os modos mais legítimos de se estabelecer as trocas científicas pelos convênios firmados, tendo como referência uma hierarquia geral da ciência (com base no modelo predominante das ciências da natureza). Aproveitar a posição em áreas específicas, como o $8^{\circ}$ lugar da educação no ranking mundial, apontado anteriormente, levaria a uma transnacionalização possível entre centros produtores em níveis similares, ampliando as formas de influência, através da publicação e da realização de projetos científicos em conjunto. Trocas científicas com países de menor relevância na produção em educação 
também poderiam se constituir numa estratégia para se aproveitar a ciência nacional de relevo, mas que, em razão da hierarquia internacional geral, recebe menor consagração. Se o inglês é a língua franca, seu uso pode ser priorizado, mas não para competir com o polo dominante, caldo de uma dinâmica de curto-circuito com a autoreferenciação de autores locados em tal núcleo, mas como um mecanismo de expansão transnacional do processo de produção e circulação do conhecimento em educação.

Artigo recebido em: 29/01/2020

Aprovado para publicação em: 30/03/2020

\section{INTERNATIONALIZATION AND TRANSNATIONALIZATION IN POSTGRADUATE EDUCATION IN BRAZIL: SOME STRUGGLES}

ABSTRACT: The article analyzes dispute surrounding the internationalization of postgraduate education in Brazil, through the study of four Education Programs (PPGEs) that, in the last evaluation of CAPES (2013-2016), obtained the maximum concept (note 7). Conducting an exploratory study of the scientific articles of the researchers of these PPGEs, with data extraction through the free software scriptLattes, we obtained 1,434 articles, $13.9 \%$ of which were published in international journals and, of these, $64 \%$ in English. Most of them (69\%) were produced in coauthorships ( 2 or more authors). Aspects of internationalization and transnationalization of knowledge production are problematized, aiming to distinguish formal mechanisms and strategies necessary for less asymmetric exchanges in the field of education.

KEYWORDS: Internationalization. Transnationalisation. Postgraduate Education Programs. Scientific production.

\section{INTERNACIONALIZACIÓN Y TRANSNACIONALIZACIÓN EN EL POSGRADO EN EDUCACIÓN EN BRASIL: ALGUNOS ENFRENTAMIENTOS}

RESUMEN: El artículo analiza el litigio en torno a la internacionalización del postgrado en Brasil, a través del estudio de cuatro Programas de Posgrado en Educación (PPGEs) que, en la última evaluación de la CAPES (2013-2016), obtuvieron el máximo concepto (nota 7). Con un estudio exploratorio de los artículos científicos de los profesores de estos PPGEs, con extracción de datos a través del software libre scriptLattes, obtuvimos 1.434 artículos, de los cuales el 13,9\% fueron publicados en revistas internacionales y, de éstos, el 64\% en inglés. La mayoría de ellos (69\%) se produjeron en coautoría ( 2 o más autores). Se problematizan los aspectos de la internacionalización y la transnacionalización de la producción de conocimientos, con el fin de distinguir los mecanismos formales y las estrategias para que los intercambios sean menos asimétricos en el ámbito de la educación.

PALABRAS CLAVE: Internacionalización. Transnacionalización. Programas de Postgrado en Educación. Producción científica. 
HEY, A. P.; CATANI, A. M.; AMORIM, A. M.

\section{NOTAS}

1) Em tradução do temo enjeux, emprestado da teoria bourdieusiana, para significar aquilo que é motivo de disputa, seja entre agentes posicionados em um campo seja entre os diferentes campos.

2) Ler a este respeito o estudo de Catani (2019).

3) O Qualis Periódicos é um instrumento da CAPES de classificação dos periódicos que contam com artigos de pesquisadores vinculados aos programas de pós-graduação no Brasil desde 1988. 4)Apenas 1 (um) artigo internacional foi publicado em alemão, razão pela qual não se encontra incluído no Quadro 3, devido a sua baixa representatividade nessa amostra.

\section{REFERÊNCIAS}

ALTBACH, P. Access means inequality. In: ALTBACH, $P$. The international imperative in higher education. Rotterdam: Sense Publishers, 2013, p. 22-24.

AUDY, J. L. N.; MOROSINI, M. C. (Org.). Inovação, universidade e internacionalização: boas práticas na PUC-RS. Porto Alegre: Edipucrs, 2010. 262 p.

AZEVEDO, M. L. N.; CATANI, A. M. Educação superior, internacionalização e circulação de ideias: ajustando os termos e desfazendo mitos. Revista Inter Ação, Goiânia, v. 38, n. 2, p. 273-291, ago. 2013.

AZEVEDO, M. L. N.; CATANI, A. M.; HEY, A. P. Circulação das ideias e internacionalização da Educação Superior: inferências a partir da teoria dos campos de Pierre Bourdieu. Educação, Porto Alegre, v. 40, n. 3, p. 296-304, set.-dez. 2017.

BOURDIEU, P. La spécifité du champ scientifique et les conditions sociales du progrés de la raisón. Sociologie et Sociétés, Paris, v. 7, n. 1, p. 91-118, mai. 1975.

BOURDIEU, P. Para uma sociologia da ciência. Lisboa: Edições 70, 2017. 166 p.

CAPES. Plano Nacional de Pós-Graduação - PNPG 2011-2020. Brasília: MEC / CAPES, 2010.

CAPES. Relatório de avaliação quadrienal 2013-2016 - Educação. Brasília: MEC/CAPES, 2017a. 79 p. Disponível em: http://avaliacaoquadrienal.capes.gov.br/resultado-da-avaliacao-quadrienal-20172/Educacao relatorio\%20de\%20avaliacao\%20quadrienal\%202017 final.pdf?attredirects $=0 \& d=1$. Acesso em: 26 mar. 2018.

CAPES. Programa de Excelência Acadêmica (Proex). Brasília: CAPES, 2017b. Disponível em: http://w.w.w.capes.gov.br/acessoainformacao/perguntas-frequentes/avaliacao-dapos-graduacao/7421-sobre-avaliacao-de-cursos. Acesso em: 16 out. 2018. 
CAPES. Qualis Periódicos. Disponível em: https://www.periodicos.capes.gov.br/. Acesso em: 02 nov. 2018.

CATANI, A. M. Novos modos de regulação e batalhas na produção do conhecimento um estudo de caso. Revista Eletrônica de Educação, São Carlos, v. 13, n. 3, p. 996-1012, set./dez. 2019.

CATANI, A. M.; OLIVEIRA, J. F. (Org.). Educação superior e produção do conhecimento: utilitarismo, internacionalização e novo contrato social. Campinas, SP: Mercado de Letras, 2015. $336 \mathrm{p}$.

CLARIVATE ANALYTICS. InCites Essential Science Indicators dataset. London: Clarivate Analytics, jun. 2019. Disponível em: https://clarivate.com/webofsciencegroup/solutions/essential-science-indicators/. Acesso em: 02 mai. 2019.

GEOCAPES. Distribuição de discentes de pós-graduação no Brasil. Brasília: CAPES, 2019. Disponível em: https://geocapes.capes.gov.br/geocapes/. Acesso em: 22 set. 2019.

HEY, A. P. Educação superior e produção do conhecimento: interfaces entre atores, instituições e políticas. In: CATANI, A. M.; OLIVEIRA, J.F. (orgs.). Educação superior e produção do conhecimento. Utilitarismo, internacionalização e novo contrato social. Campinas, SP: Mercado de Letras, 2015, v. 1, p. 231-252.

LEYDESDORFF, L.; WOUTERS, P.; BORNMANN, L. Professional and citizen bibliometrics: complementarities and ambivalences in the development and use of indicators-a stateof-the-art report. Scientometrics, New York, v. 109, n. 3, p. 2129-2150, 2016.

MARTINS, C. B. Notas sobre a formação de um sistema transnacional de ensino superior. Cadernos CRH, Salvador, v. 28, n. 74, p. 291-308, mai./ago. 2015.

MUGNAINI, R.; LETA, J.; LEITE, P. A new indicator for international visibility: exploring brazilian scientific community. Scientometrics, Amsterdã, v. 88, p. 311-319, apr. 2011.

OCDE. Education at a glance. Paris: OCDE, 2019. Disponível em: http://portal.inep.gov.br/informacao-da-publicacao/lasset publisher/6JYIsGMAMkW1/document/id/6736149. Acesso em: 10 jan. 2020.

OLIVEIRA, T. M.; AMARAL, L. Políticas públicas em ciência e tecnologia no Brasil: desafios e propostas para utilização de indicadores na avaliação. In: MUGNAINI, R.; FUJINO, A.; KOBASHI, N. (Org.). Bibliometria e cientometria no Brasil: infraestrutura para avaliação da pesquisa científica na era do Big Data. São Paulo: ECA/USP, 2017. p. 157-188. 
HEY, A. P.; CATANI, A. M.; AMORIM, A. M

SAPIRO, G. (Coord.). L'espace intellectuel en Europe. Paris: La Découverte, 2009.

SAPIRO, G.; LEPERLIER, T.; BRAHIMI, M. A. Qu'est-ce qu'un champ intellectuel transnational? Actes de la recherche en sciences sociales, Paris, n. 224, p. 4-11, sept. 2018.

SANTIN, D. M.; VANZ, S. A. S.; STUMPF, I. R. C. Internacionalização da produção científica brasileira: políticas, estratégias e medidas de avaliação. Revista Brasileira de PósGraduação, Brasília, v. 13, n. 30, p. 81-100, jan./abr. 2016.

SCIMAGO journal and country rank. Madrid: SCImago Lab, 2019. Disponível em: https://www.scimagojr.com/countryrank.php. Acesso em: 9 nov. 2019.

SILVEIRA, E. Fuga de cérebros: os doutores que preferiram deixar o Brasil para continuar pesquisas em outro país. BBC Brasil, 18 jan. 2020. Disponível em: https://www.bbc.com/portuguese/brasil-51110626. Acesso em: 20 jan. 2020.

TROW, M. A. Reflections on the transition from elite to mass to universal access: forms and phases of higher education in modern societies since WWII. Berkeley: University of California, 2005.

WAGNER, A. C. Mundialização/internacionalização. In: CATANI, A. M. et al. Vocabulário Bourdieu. Belo Horizonte: Autêntica, 2017, p. 272-274.

Ana Paula Hey: Possui Pós-doutorado em Sociologia pelo King's College London (2015-16). É doutora em Educação (Sociologia da Educação) pela Universidade Federal de São Carlos (2004), com estágio de pesquisa na École des Hautes Études en Sciences Sociales, Paris/França (2001-04).

Orcid: https://orcid.org/0000-0003-3513-8598

E-mail: anahey@usp.br

AfrãnIo Mendes Catani: Professor Titular aposentado na Faculdade de Educação da Universidade de Sao Paulo (USP) e Professor visitante junto à Faculdade de Educação da Universidade Federal Fluminense (UFF). Mestre e Doutor em Sociologia pela Faculdade de Filosofia, Letras e Ciências Humanas da USP, Livre Docente em Educação pela FEUSP, com Pós-doutorado na Middlesex University London, UK. Autor de dezenas de artigos, livros e capítulos de livros nos domínios das políticas de educação superior na América Latina, da história do cinema latino-americano e português, da sociologia da educação e da cultura.

Orcid: https://orcid.org/0000-0003-0656-3931

E-mail: amcatani@usp.br 
Antônio Marcos Amorim: Cursa o Doutorado em Cultura, Filosofia e História da Educação pela Faculdade de Educação da USP. Possui Mestrado em Ciências da Comunicação (2002) e Graduação em Ciência da Informação (1995), ambas pela Escola de Comunicações e Artes da USP. É atualmente Chefe técnico da Biblioteca do Conjunto das Químicas da USP e desenvolve projetos nesta, além de realizar capacitações no uso de bases de dados, portais de Teses e de revistas, desde 2018. É membro do Centro de Memória da Faculdade de Ciências Farmacêuticas da USP (CEMEF).

Orcid: https://orcid.org/0000-0002-1438-3685

E-mail: amarcos@usp.br

Este periódico utiliza a licença Creative Commons Attribution 3.0, para periódicos de acesso aberto (Open Archives Iniciative - OAI). 